\title{
Parent psychopathology and offspring mental disorders: results from the WHO World Mental Health Surveys
}

Katie A. McLaughlin, Anne M. Gadermann, Irving Hwang, Nancy A. Sampson, Ali Al-Hamzawi, Laura Helena Andrade, Matthias C. Angermeyer, Corina Benjet, Evelyn J. Bromet, Ronny Bruffaerts, José Miguel Caldas-de-Almeida, Giovanni de Girolamo, Ron de Graaf, Silvia Florescu, Oye Gureje, Josep Maria Haro, Hristo Ruskov Hinkov, Itsuko Horiguchi, Chiyi Hu, Aimee Nasser Karam, Viviane Kovess-Masfety, Sing Lee, Samuel D. Murphy, S. Haque Nizamie, José Posada-Villa, David R. Williams and Ronald C. Kessler

\section{Background}

Associations between specific parent and offspring mental disorders are likely to have been overestimated in studies that have failed to control for parent comorbidity.

\section{Aims \\ To examine the associations of parent with respondent disorders.}

\section{Method}

Data come from the World Health Organization (WHO) World Mental Health Surveys $(n=51507)$. Respondent disorders were assessed with the Composite International Diagnostic Interview and parent disorders with informantbased Family History Research Diagnostic Criteria interviews.

\section{Results}

Although virtually all parent disorders examined (major depressive, generalised anxiety, panic, substance and antisocial behaviour disorders and suicidality) were significantly associated with offspring disorders in multivariate analyses, little specificity was found. Comorbid parent disorders had significant sub-additive associations with offspring disorders. Population-attributable risk proportions for parent disorders were $12.4 \%$ across all offspring disorders, generally higher in high- and uppermiddle- than low-/lower-middle-income countries, and consistently higher for behaviour (11.0-19.9\%) than other (7.1-14.0\%) disorders.

\section{Conclusions}

Parent psychopathology is a robust non-specific predictor associated with a substantial proportion of offspring disorders.

\section{Declaration of interest}

R.C.K. has been a consultant for Astrazeneca, Analysis Group, Bristol-Myers Squibb, Cerner-Galt Associates, Eli Lilly \& Company, GlaxoSmithKline, HealthCore, Health Dialog, Integrated Benefits Institute, John Snow, Kaiser Permanente, Matria, Mensante, Merck \& Co, Ortho-McNeil Janssen Scientific Affairs, Pfizer, Primary Care Network, Research Triangle Institute, Sanofi-Aventis Groupe, Shire US, SRA International, Takeda Global Research \& Development, Transcept Pharmaceuticals and Wyeth-Ayerst; has served on advisory boards for Appliance Computing II, Eli Lilly \& Company, Mindsite, Ortho-McNeil Janssen Scientific Affairs, Plus One Health Management and Wyeth-Ayerst; and has had research support for his epidemiological studies from Analysis Group, Bristol-Myers Squibb, Eli Lilly \& Company, EPI-Q, GlaxosmithKline, Johnson \& Johnson Pharmaceuticals, Ortho-McNeil Janssen Scientific Affairs, Pfizer, Sanofi-Aventis Groupe and Shire US.
Parent psychopathology is strongly associated with offspring psychiatric disorders, ${ }^{1-6}$ a risk transmitted through both genetic and environmental mechanisms. ${ }^{4-9}$ A central unresolved question, though, is whether having a parent with a mental disorder creates a generalised vulnerability to psychopathology or whether particular parent disorders are associated with particular offspring disorders. ${ }^{2}$ Numerous studies have examined familial aggregation of psychiatric disorders and found that some disorders appear to 'breed true' in families (for example, parental anxiety is associated with an increased risk for offspring anxiety), ${ }^{3,5,10,11}$ although the pattern of associations differs by disorder. ${ }^{10,12}$ However, much of this research examined a single or limited number of parent disorders without accounting for comorbidity among parent disorders, ${ }^{1,5,6,10}$ which may have artificially inflated estimates of associations between specific parent and offspring disorders. Indeed, evidence from a national sample found that the familial aggregation of some mental disorders was substantially attenuated by adjusting for comorbid parent disorders. ${ }^{12}$ Several small family studies have reported a similar result. ${ }^{13,14}$ An additional problem is that those that considered comorbidity among parent disorders assumed additive associations. Given emerging evidence of the existence of subadditive interactions - that is, the effects of comorbid disorders are less than the sum of their individual effects due to the incremental predictive power of individual disorders decaying as the number of comorbid disorders increases - both among temporally primary mental disorders in predicting secondary comorbid disorders $^{15}$ and among childhood adversities in predicting mental disorders, ${ }^{16,17}$ this assumption of additivity needs to be reconsidered. The World Health Organization (WHO) World Mental Health (WMH) Surveys offer a unique opportunity to do so. We provide the first cross-national examination of the associations of parent disorders with offspring disorders from WMH surveys in 22 countries.

\section{Method}

\section{Sample}

The WMH Surveys were carried out in ten countries classified by the World Bank as high income (Belgium, France, Germany, Italy, 
Japan, The Netherlands, Northern Ireland, Portugal, Spain, USA), six classified as upper-middle income (Brazil, Bulgaria, Lebanon, Mexico, Romania, South Africa) and six classified as low/lowermiddle income (Colombia, India, Iraq, Nigeria, Peoples Republic of China, Ukraine) ${ }^{18}$ (online Table DS1). Individual country sample sizes ranged from 2357 (Romania) to 9282 (USA). Respondents were selected in most countries using a stratified multistage clustered-area probability sampling strategy in which samples were either nationally or regionally representative. The weighted average response rate across all countries was $71.8 \%$.

Surveys were administered face to face in respondents' households by trained lay interviewers. Interviews were completed in two parts in all countries except Romania and South Africa, where all respondents completed the entire survey. The Part I interview was administered to all respondents and assessed the presence of core DSM-IV ${ }^{19}$ mental disorders. Part II assessed additional disorders as well as disorder correlates. The Part II interview was administered to a probability subsample of Part I respondents that included $100 \%$ of those who met lifetime criteria for any Part I mental disorder and a probability subsample of approximately $25 \%$ of other respondents. Cases in the Part II sample were weighted by the inverse of their probability of selection to adjust for differential sampling. The current analyses were based on the weighted Part II sample $(n=51507)$. Additional weights adjusted for differential probabilities of selection within and between households and matched the samples to population sociodemographic and geographic distributions. A fuller description of these procedures is provided elsewhere. ${ }^{20-22}$ Recruitment and consent procedures were approved by the local human subjects committee that monitored the study in each country.

\section{Measures}

\section{Mental disorders}

Mental disorders were assessed with the WHO Composite International Diagnostic Interview (CIDI) Version $3.0,{ }^{23}$ a fully structured lay-administered interview that generated diagnoses for 20 lifetime mental disorders, including mood (major depression/dysthymia, bipolar I, II and subthreshold), anxiety (generalised anxiety disorder, panic disorder, agoraphobia without panic disorder, specific phobia, social phobia, post-traumatic stress disorder, separation anxiety disorder), behaviour (attention-deficit hyperactivity disorder (ADHD), oppositionaldefiant disorder, conduct disorder, intermittent explosive disorder) and substance disorders (alcohol and drug misuse, alcohol and drug dependence with misuse). The study used DSM-IV organic exclusion and diagnostic hierarchy rules (other than for oppositional-defiant disorder, which was defined with or without conduct disorder, and substance misuse, which was defined with or without dependence). As detailed elsewhere, ${ }^{24}$ masked clinical reappraisal interviews with the Structured Clinical Interview for DSM-IV (SCID) ${ }^{25}$ in four WMH countries found generally good concordance between diagnoses based on the CIDI and SCID, with area under the receiver operating characteristic curve of $0.75-0.93$ for mood disorders, $0.65-0.81$ for anxiety disorders, $0.62-0.88$ for substance disorders and 0.86 for ADHD. ${ }^{24}$ Age at onset of lifetime disorders was assessed retrospectively using a special question sequence that has been shown experimentally to yield more plausible distributions than standard age-at-onset questions. ${ }^{26}$ The prevalence of respondent disorders has been reported previously, ${ }^{27}$ and is shown in online Table DS2.

\section{Parent psychopathology}

Parent disorders were assessed with an expanded version of the Family History Research Diagnostic Criteria Interview
(FHRDCI). ${ }^{28,29}$ Respondents reported parent disorders that were present during at least some part of their childhoods. The disorders assessed included major depressive episodes, panic disorder, generalised anxiety disorder, substance dependence and antisocial personality disorder as well as parent suicide attempt and suicide death. Each type of parent disorder was coded present if the respondent reported it for either his/her mother or father. The FHRCDI has high interrater reliability, ${ }^{29}$ good predictive validity $^{30}$ and good diagnostic agreement between offspring reports and parent interviews. ${ }^{31}$ The prevalence of reported parent disorders is shown in online Table DS3.

\section{Analysis methods}

The associations between parent psychopathology and lifetime occurrence of respondent disorders were estimated in a series of discrete-time survival models with person-year as the unit of analysis $^{32}$ and controls for country, respondent age at interview and gender. We first examined a series of bivariate models in which each type of parent disorder was considered individually as a predictor of the full range of respondent disorders. We then estimated a set of multivariate models in which all parent disorders were considered simultaneously in predicting respondent disorders. Subsequent models examined the associations of either (a) number of parent disorders or (b) both number and type of parent disorders with respondent disorders. Each model began by using a consolidated set of 17 separate person-year data files that focused on a single respondent outcome disorder (major depression/dysthymia, and bipolar I, II and subthreshold were each examined in a single person-year file); this forced the estimated slopes of respondent disorders on parent disorders to be constant across outcomes. We then disaggregated this consolidated set of files to predict first onset of disorders within each of four broad disorder classes (mood, anxiety, substance and behaviour disorders).

The population attributable risk proportion (PARP) of respondent disorders predicted by parent disorders was computed for the best-fitting multivariate model using simulation methods that generated individual-level predicted probabilities of the outcome disorders from the coefficients in the model with and without coefficients for parent disorders. The PARP can be interpreted as the proportion of the observed outcomes that would not have occurred in the absence of one or more predictors based on the assumption that the coefficients in the model represents causal effects of the predictor. Survival coefficients and their standard errors were exponentiated and presented as odds ratios (ORs) with 95\% confidence intervals. To adjust for sample weighting and clustering, standard errors were estimated using the Taylor series method $^{33}$ implemented in the SUDAAN (version 8.01) software system on Unix. Statistical significance was consistently evaluated using 0.05 level two-sided tests.

\section{Results}

\section{Preliminary analysis}

We first conducted preliminary tests to determine whether the associations between parent and offspring mental disorders differed depending on which parent (i.e. mother or father) had the disorder, how many parents had the disorder (i.e. one or both) and whether the respondent was a male or female. These analyses showed that the associations consistently differed depending on whether one or both parents had a disorder, with the exception of parent suicide death. All subsequent models therefore included separate dummy variables coding whether one or both parents had each disorder and whether either parent had died by suicide. As distinguishing between whether a respondent's mother or 
father had the disorder influenced only the associations involving parent substance misuse, an additional predictor was included in the final specification to distinguish maternal from paternal substance misuse. Gender of the respondent did not interact with any parent disorder. We also evaluated whether parent suicide attempt and death contributed unique information in predicting offspring disorders or whether they could be combined into a single suicidality indicator. These analyses suggested that both indicators had unique associations with offspring disorders; they were therefore retained as separate variables in all analyses. Parent death by suicide was the only type of parent psychopathology entered as a time-varying covariate, as information was not available on the respondent's age when each parent disorder started. We knew only that the parent disorder was present for at least some of the respondent's childhood, and we coded these disorders as time-invariant predictors.

\section{Associations of parent disorders with offspring disorders}

In bivariate models that considered only one type of parent disorder at a time, all parent disorders are significant predictors of lifetime onset of offspring DSM-IV/CIDI disorders in pooled models that combined estimates across all offspring disorders (Table 1). Odds ratios are in the range 1.8-2.9 for one parent having a given disorder and 2.2-4.6 for both parents having a disorder. In all cases, the odds are higher if both parents had the disorder than if only one did. A similar pattern is observed in bivariate models predicting each of the four disorder classes. Each type of parent disorder significantly predicts each of the four types of offspring disorders, with the exception of parent death by suicide. Within-class associations (such as parent depression predicting offspring mood disorders) are somewhat higher than across-class associations (such as parent depression predicting offspring behaviour disorders). However, this pattern is not pronounced and there are notable exceptions to it, such as parent generalised anxiety disorder having an odds ratio as large as that of parent depression in predicting offspring mood disorders, and parent generalised anxiety disorder as well as parent depression both having higher odds ratios than parent antisocial personality disorder in predicting offspring behaviour disorders.

The bivariate associations are uniformly attenuated in the additive multivariate model (Table 2). Five of the seven types of parent psychopathology are significantly associated with offspring mental disorders in the pooled model (odds ratios in the range 1.3-1.9 for one parent and 1.5-2.2 for both parents). Neither parent suicide attempt nor suicide death are associated with offspring disorders in this model. The odds of offspring disorder was higher if both parents had the disorder only in the cases of parent panic disorder and substance misuse. A test for the joint associations of all parent disorders in this model was significant $\left(\chi_{14}^{2}=1437.5, P<0.001\right)$.

Disaggregation of this model by type of offspring disorders reveals little variation. All types of parent disorder other than suicide attempt and suicide death predict offspring mood, anxiety

\begin{tabular}{|c|c|c|c|c|c|c|c|c|c|c|}
\hline \multirow[b]{3}{*}{ Parent disorder } & \multicolumn{10}{|c|}{ Offspring disorder } \\
\hline & \multicolumn{2}{|c|}{ Any disorder } & \multicolumn{2}{|c|}{ Mood disorder } & \multicolumn{2}{|c|}{ Anxiety disorder } & \multicolumn{2}{|c|}{ Substance disorder } & \multicolumn{2}{|c|}{ Behaviour disorder } \\
\hline & OR $(95 \% \mathrm{Cl})$ & $\chi^{2}$ & OR $(95 \% \mathrm{Cl})$ & $\chi^{2}$ & OR $(95 \% \mathrm{Cl})$ & $\chi^{2}$ & OR $(95 \% \mathrm{Cl})$ & $\chi^{2}$ & OR $(95 \% \mathrm{Cl})$ & $\chi^{2}$ \\
\hline I. Depression ${ }^{\mathrm{b}}$ & & $451.8^{*}$ & & $307.9^{*}$ & & $389.0^{*}$ & & $113.6^{*}$ & & $253.5^{\star}$ \\
\hline Exactly 1 parent & $2.8^{*}(2.5-3.1)$ & & $2.6^{*}(2.3-2.9)$ & & $2.8^{*}(2.5-3.2)$ & & $2.5^{\star}(2.1-3.0)$ & & $3.6^{*}(3.0-4.2)$ & \\
\hline Both parents & $4.0 *(2.9-5.4)$ & & $4.0 *(2.8-5.6)$ & & $4.1^{*}(2.9-5.8)$ & & $2.5^{*}(1.3-4.7)$ & & $5.2 *(3.4-8.1)$ & \\
\hline II. $G A D^{b}$ & & $710.0 *$ & & $449.0 *$ & & $619.2^{\star}$ & & $169.8^{*}$ & & $1234.5^{\star}$ \\
\hline Exactly 1 parent & $2.9 *(2.6-3.2)$ & & $2.7 *(2.4-3.0)$ & & $3.0 *(2.7-3.3)$ & & $2.4^{*}(2.0-2.8)$ & & $\begin{array}{c}41.9^{*} \\
(34.0-51.7)\end{array}$ & \\
\hline Both parents & $4.6^{*}(3.7-5.8)$ & & $4.0 *(3.1-5.2)$ & & $4.6 *(3.6-5.9)$ & & $4.4^{*}(2.9-6.5)$ & & $\begin{array}{l}6303.1^{*} \\
(2455.3- \\
16181.2)^{c}\end{array}$ & \\
\hline III. Panic disorder ${ }^{\text {b }}$ & & $782.9^{*}$ & & $479.8^{*}$ & & $730.7^{*}$ & & $201.5^{\star}$ & & $278.5^{\star}$ \\
\hline Exactly 1 parent & $2.5^{*}(2.3-2.6)$ & & $2.3^{*}(2.1-2.5)$ & & $2.6^{*}(2.4-2.8)$ & & $2.2^{*}(2.0-2.5)$ & & $2.8^{*}(2.4-3.2)$ & \\
\hline Both parents & $3.7 *(3.1-4.4)$ & & $3.1 *(2.5-3.9)$ & & $4.1^{*}(3.3-5.0)$ & & $3.2^{*}(2.4-4.3)$ & & $4.6 *(3.5-6.2)$ & \\
\hline IV. Substance misuse ${ }^{d}$ & & $445.3^{*}$ & & $221.3^{*}$ & & $309.0^{*}$ & & $364.5^{\star}$ & & $156.2^{*}$ \\
\hline $\begin{array}{l}\text { Exactly } 1 \text { parent - } \\
\text { mother }\end{array}$ & $2.5^{\star}(2.1-3.0)$ & & $2.2^{*}(1.7-2.7)$ & & $2.1^{*}(1.7-2.6)$ & & $3.2^{\star}(2.5-4.0)$ & & $3.2^{*}(2.4-4.3)$ & \\
\hline $\begin{array}{l}\text { Exactly } 1 \text { parent - } \\
\text { father }\end{array}$ & $2.0 *(1.8-2.2)$ & & $1.8^{*}(1.6-2.0)$ & & $1.8^{*}(1.7-2.0)$ & & $2.4^{*}(2.1-2.7)$ & & $2.4^{*}(2.0-2.9)$ & \\
\hline Both parents & $3.1 *(2.4-4.1)$ & & $2.3^{*}(1.6-3.2)$ & & $3.0 *(2.3-4.1)$ & & $4.3^{*}(3.0-6.1)$ & & $3.7^{*}(2.6-5.2)$ & \\
\hline $\begin{array}{l}\text { V. Antisocial personality } \\
\text { disorder }^{\text {b }}\end{array}$ & & $368.7^{*}$ & & $142.2^{*}$ & & $267.0^{*}$ & & $209.0^{*}$ & & $189.0^{*}$ \\
\hline Exactly 1 parent & $2.5^{\star}(2.3-2.8)$ & & $2.1^{*}(1.9-2.4)$ & & $2.4^{*}(2.1-2.7)$ & & $2.6 *(2.3-3.0)$ & & $3.5^{*}(2.9-4.2)$ & \\
\hline Both parents & $3.0 *(1.8-5.0)$ & & $2.0 *(1.1-3.8)$ & & $2.8^{*}(1.5-5.1)$ & & $3.7 *(2.1-6.6)$ & & $4.0 *(2.4-6.7)$ & \\
\hline VI. Suicide attempt ${ }^{b}$ & & $113.2^{*}$ & & $90.9 *$ & & $79.1^{*}$ & & $39.1^{\star}$ & & $73.7^{\star}$ \\
\hline Exactly 1 parent & $1.8^{*}(1.6-2.1)$ & & $1.8^{*}(1.6-2.0)$ & & $1.8^{*}(1.6-2.0)$ & & $1.8^{*}(1.5-2.2)$ & & $2.3^{*}(1.9-2.8)$ & \\
\hline Both parents & $2.2^{*}(1.1-4.4)$ & & $2.2^{*}(1.0-4.8)$ & & $2.3^{*}(1.0-5.4)$ & & $1.0(0.4-2.3)$ & & $3.5^{*}(1.6-7.5)$ & \\
\hline $\begin{array}{l}\text { VII. Suicide (death from } \\
\text { suicide) }^{\mathrm{e}}\end{array}$ & & $4.9^{*}$ & & $7.0^{*}$ & & 1.6 & & 2.1 & & 0.1 \\
\hline Any & $1.5^{\star}(1.0-2.0)$ & & $1.6^{*}(1.1-2.2)$ & & $1.3(0.9-2.0)$ & & $1.6(0.8-3.3)$ & & $1.2(0.4-3.5)$ & \\
\hline $\begin{array}{l}\text { GAD, generalised anxiety di } \\
\text { a. Assessed in the Part II sa } \\
\text { b. For } \chi^{2} \text { d.f. }=2 \text {. } \\
\text { c. Although the number of } \\
\text { that the association betwee } \\
\text { d. For } \chi^{2} \text { d.f. }=3 \text {. } \\
\text { e. Parent death from suicid } \\
\text { * Significant at the } 0.05 \text { leve }\end{array}$ & $\begin{array}{l}\text { sorder. } \\
\text { ample. Models con } \\
\text { respondents who } \\
\text { both-parent GA } \\
\text { e is a time-varying } \\
\text { l, two-sided test. }\end{array}$ & $\begin{array}{l}\text { ol for cou } \\
\text { ported th } \\
\text { and offsp } \\
\text { oredictor; }\end{array}$ & $\begin{array}{l}\text { ry, person-year, a } \\
\text { both their parents } \\
\text { g behaviour disor } \\
\text { other parent diso }\end{array}$ & $\begin{array}{l}\text { and genc } \\
\text { had GAD } \mathrm{i} \\
\text { ers is stati } \\
\text { ders are } \mathrm{C}\end{array}$ & $\begin{array}{l}\text { small, the consist } \\
\text { scally significant d } \\
\text { isidered time-inva }\end{array}$ & $\begin{array}{l}\text { ncy of the } \\
\text { spite the it } \\
\text { lant. For } \chi\end{array}$ & $\begin{array}{l}\text { respondents havi } \\
\text { tability of the OR } \\
\text { d.f. }=1 \text {. }\end{array}$ & $\begin{array}{l}\text { g multiple } \\
\text { hd } \mathrm{Cl} \text {. }\end{array}$ & haviour disorde & s so great \\
\hline
\end{tabular}




\begin{tabular}{|c|c|c|c|c|c|c|c|c|c|c|}
\hline \multirow[b]{3}{*}{ Parent disorder } & \multicolumn{10}{|c|}{ Offspring disorder } \\
\hline & \multicolumn{2}{|c|}{ Any disorder } & \multicolumn{2}{|c|}{ Mood disorder } & \multicolumn{2}{|c|}{ Anxiety disorder } & \multicolumn{2}{|c|}{ Substance disorder } & \multicolumn{2}{|c|}{ Behaviour disorder } \\
\hline & OR $(95 \% \mathrm{Cl})$ & $\chi^{2}$ & OR $(95 \% \mathrm{Cl})$ & $\chi^{2}$ & OR $(95 \% \mathrm{Cl})$ & $\chi^{2}$ & OR $(95 \% \mathrm{Cl})$ & $\chi^{2}$ & OR $(95 \% \mathrm{Cl})$ & $\chi^{2}$ \\
\hline \multirow{3}{*}{$\begin{array}{l}\text { I. Depression }{ }^{\mathrm{b}} \\
\text { Exactly } 1 \text { parent } \\
\text { Both parents }\end{array}$} & & $18.9 *$ & & $16.9 *$ & & $18.6^{*}$ & & 3.6 & & $10.5^{*}$ \\
\hline & $1.3^{*}(1.2-1.5)$ & & $1.3^{*}(1.2-1.5)$ & & $1.3^{*}(1.2-1.5)$ & & $1.2(1.0-1.6)$ & & $1.4^{*}(1.2-1.8)$ & \\
\hline & $1.3(0.9-1.9)$ & & $1.5^{\star}(1.0-2.3)$ & & $1.4(0.9-2.1)$ & & $0.8(0.3-1.8)$ & & $1.2(0.8-1.9)$ & \\
\hline \multirow{3}{*}{$\begin{array}{l}\text { II. GAD } \\
\text { Exactly } 1 \text { parent } \\
\text { Both parents }\end{array}$} & & $59.2^{*}$ & & $38.9 *$ & & $67.7^{\star}$ & & 4.4 & & $24.6^{*}$ \\
\hline & $1.6^{*}(1.4-1.7)$ & & $1.6^{*}(1.4-1.8)$ & & $1.7 *(1.5-1.9)$ & & $1.2(1.0-1.5)$ & & $1.7^{*}(1.4-2.1)$ & \\
\hline & $1.5^{*}(1.0-2.1)$ & & $1.5^{*}(1.0-2.1)$ & & $1.5^{*}(1.1-2.2)$ & & $1.5(0.8-2.7)$ & & $1.7^{*}(1.1-2.5)$ & \\
\hline \multirow{3}{*}{$\begin{array}{l}\text { III. Panic disorder } \\
\text { Exactly } 1 \text { parent } \\
\text { Both parents }\end{array}$} & & $291.6^{*}$ & & $168.9^{*}$ & & $267.1^{*}$ & & $63.0 *$ & & $96.6^{*}$ \\
\hline & $1.9^{*}(1.7-2.0)$ & & $1.8^{*}(1.7-2.0)$ & & $2.0 *(1.8-2.1)$ & & $1.7^{*}(1.5-2.0)$ & & $1.9 *(1.7-2.2)$ & \\
\hline & $2.2^{*}(1.8-2.7)$ & & $1.9 *(1.5-2.5)$ & & $2.4^{*}(2.0-3.0)$ & & $2.2^{*}(1.6-3.1)$ & & $2.2^{*}(1.6-3.0)$ & \\
\hline \multirow{4}{*}{$\begin{array}{l}\text { IV. Substance misuse } \\
\text { Exactly } 1 \text { parent - } \\
\text { mother } \\
\text { Exactly } 1 \text { parent - } \\
\text { father } \\
\text { Both parents }\end{array}$} & & $82.1^{*}$ & & $33.5^{\star}$ & & $35.4^{*}$ & & $122.2^{*}$ & & $22.1^{*}$ \\
\hline & $1.4^{*}(1.1-1.7)$ & & $1.2(0.9-1.5)$ & & $1.1(0.9-1.4)$ & & $2.0 *(1.5-2.7)$ & & $1.6 *(1.1-2.2)$ & \\
\hline & $1.4^{*}(1.3-1.6)$ & & $1.3^{*}(1.2-1.5)$ & & $1.3^{*}(1.2-1.4)$ & & $1.9^{*}(1.6-2.2)$ & & $1.5^{*}(1.2-1.9)$ & \\
\hline & $1.9 *(1.4-2.4)$ & & $1.4^{*}(1.0-2.0)$ & & $1.7^{*}(1.3-2.2)$ & & $3.0 *(2.2-4.3)$ & & $1.8^{*}(1.3-2.6)$ & \\
\hline \multicolumn{2}{|c|}{$\begin{array}{l}\text { V. Antisocial personality } \\
\text { disorder }^{\text {b }}\end{array}$} & $64.2^{\star}$ & & $15.3^{*}$ & & $47.7^{\star}$ & & $28.9^{*}$ & & $32.7^{*}$ \\
\hline Exactly 1 parent & $1.5^{*}(1.4-1.7)$ & & $1.3^{*}(1.2-1.5)$ & & $1.5^{*}(1.3-1.7)$ & & $1.5^{*}(1.3-1.7)$ & & $1.9 *(1.5-2.3)$ & \\
\hline Both parents & $1.5(1.0-2.2)$ & & $1.0(0.6-1.7)$ & & $1.4(0.9-2.2)$ & & $1.6(0.8-3.2)$ & & $1.6(0.9-2.6)$ & \\
\hline \multirow{3}{*}{$\begin{array}{l}\text { VI. Suicide attempt } \\
\text { Exactly } 1 \text { parent } \\
\text { Both parents }\end{array}$} & & 1.6 & & 1.5 & & 0.2 & & 5.9 & & 0.9 \\
\hline & $1.1(0.9-1.2)$ & & $1.1(0.9-1.2)$ & & $1.0(0.9-1.2)$ & & $1.1(0.9-1.3)$ & & $1.1(0.9-1.4)$ & \\
\hline & $0.8(0.4-1.5)$ & & $1.1(0.6-2.0)$ & & $0.9(0.4-1.8)$ & & $0.3^{*}(0.1-0.8)$ & & $1.0(0.5-2.1)$ & \\
\hline \multicolumn{11}{|l|}{ VII. Suicide (death from } \\
\hline Any & $1.3(0.9-1.7)$ & & $1.3(1.0-1.9)$ & & $1.2(0.8-1.7)$ & & $1.5(0.8-2.9)$ & & $1.0(0.3-2.8)$ & \\
\hline Global $^{e}$ & & $1437.5^{*}$ & & $842.8^{*}$ & & $1263.6^{*}$ & & $641.0^{*}$ & & $891.3^{*}$ \\
\hline \multicolumn{11}{|c|}{$\begin{array}{l}\text { GAD, generalised anxiety disorder. } \\
\text { a. Assessed in the Part II sample. Models include dummy variables for all parent mental disorders and control for country, person-year, age and gender. } \\
\text { b. For } \chi^{2} \text { d.f. }=2 \text {. } \\
\text { c. For } \chi^{2} \text { d.f. }=3 \text {. } \\
\text { d. Parent death from suicide is a time-varying predictor; all other parent disorders are not time-varying. For } \chi^{2} \text { d.f. }=1 \text {. } \\
\text { e. For } \chi^{2} \text { d.f. }=14 \text {. Global chi-squared test for the joint associations of all parent disorder types with each of the offspring outcome disorder classes. } \\
\text { *Significant at the } 0.05 \text { level, two-sided test. }\end{array}$} \\
\hline
\end{tabular}

and behaviour disorders. The one exception is offspring substance disorders, where parent generalised anxiety disorder and depression are not significant predictors. The joint associations of all parent disorders as a set are significant in predicting all four classes of offspring disorders $\left(\chi^{2}{ }_{14}=641.0-1263.6, P<0.001\right)$. Within-class associations are generally stronger than across-class associations, with two exceptions. First, parent generalised anxiety disorder and panic disorder are stronger predictors than parent depression of offspring mood disorders. Second, parent panic disorder is as strong a predictor as parent antisocial personality disorder of offspring behaviour disorders.

\section{Associations of number of parent disorders with offspring disorders}

A generally increasing association exists between number of parent disorders and odds of offspring disorders in the pooled model, with odds ratios ranging from 1.9 for exactly one maternal disorder to 3.0-3.6 for five and six or more maternal disorders (Table 3). The odds ratios increase from 1.6 for exactly one paternal disorder to 2.8 for exactly four paternal disorders and then decrease to 1.9-2.0 for five and six or more paternal disorders. The joint associations of number-of-parental disorders with pooled offspring disorders is significant for both maternal $\left(\chi^{2}{ }_{5}=580.8, \quad P<0.001\right)$ and paternal $\left(\chi^{2}{ }_{5}=346.7, \quad P<0.001\right)$ disorders.

Disaggregation of this model shows a similar pattern in predicting each class of offspring disorders, with joint associations of both maternal and paternal number-of-disorders significant in predicting each class of offspring disorders $\left(\chi^{2}{ }_{5}=114.9-515.7\right.$, $P<0.001)$. A monotonic dose-response relationship exists between number of maternal disorders and odds of offspring substance disorder.

\section{Associations of type-number of parent disorders with offspring disorders}

We next estimated a series of multivariate models that included both type and number of parent disorders as predictors (Table 4). Each type of parent disorder is significantly associated with odds of offspring disorders in the pooled model (odds ratios in the range 1.4-2.1 for one parent and 1.5-3.0 for both parents), controlling for number of disorders. Types of parent disorders are significant as a set after controlling for number of disorders $\left(\chi_{14}^{2}=670.0, P<0.001\right)$. The odds ratio associated with parent disorder types in this model are generally higher than in the additive model. This means that the additivity assumption led to a downward bias in the estimated associations of parent disorders with offspring disorders in the earlier model. This bias occurred because the odds ratios associated with number of parent disorders are significant as a set $\left(\chi_{5}^{2}=74.1, P<0.001\right.$ for maternal disorders and $\chi^{2}{ }_{5}=70.5, P<0.001$ for paternal disorders) and consistently less than 1.0 in the pooled model that includes terms for both type and number of disorders. This pattern of associations suggests the presence of sub-additive interactions among comorbid parent disorders; that is, the odds ratios of 
Table 3 Multivariate associations between number of parent disorders and subsequent onset of offspring lifetime DSM-IV/CIDI disorders $^{\text {a }}$

\begin{tabular}{|c|c|c|c|c|c|c|c|c|c|c|}
\hline \multirow[b]{3}{*}{ Parent disorder } & \multicolumn{10}{|c|}{ Offspring disorder } \\
\hline & \multicolumn{2}{|c|}{ Any disorder } & \multicolumn{2}{|c|}{ Mood disorder } & \multicolumn{2}{|c|}{ Anxiety disorder } & \multicolumn{2}{|c|}{ Substance disorder } & \multicolumn{2}{|c|}{ Behaviour disorder } \\
\hline & OR $(95 \% \mathrm{Cl})$ & $\chi^{2}$ & OR $(95 \% \mathrm{Cl})$ & $\chi^{2}$ & OR $(95 \% \mathrm{Cl})$ & $\chi^{2}$ & OR $(95 \% \mathrm{Cl})$ & $\chi^{2}$ & OR $(95 \% \mathrm{Cl})$ & $\chi^{2}$ \\
\hline \multicolumn{10}{|l|}{ I. Number of maternal } & $249.6^{*}$ \\
\hline 1 & $1.9 *(1.8-2.1)$ & & $1.8^{*}(1.7-2.0)$ & & $2.0 *(1.9-2.2)$ & & $1.8^{*}(1.6-2.1)$ & & $1.9 *(1.7-2.3)$ & \\
\hline 2 & $2.2^{*}(1.9-2.5)$ & & $2.2^{*}(1.8-2.6)$ & & $2.1 *(1.8-2.5)$ & & $2.0 *(1.6-2.6)$ & & $2.5^{*}(2.0-3.1)$ & \\
\hline 3 & $3.2^{*}(2.7-3.7)$ & & $3.0 *(2.5-3.6)$ & & $3.3^{*}(2.7-3.9)$ & & $2.4^{*}(1.7-3.4)$ & & $4.2 *(3.3-5.3)$ & \\
\hline 4 & $2.8 *(2.1-3.8)$ & & $2.2^{*}(1.6-3.1)$ & & $2.5^{*}(1.8-3.4)$ & & $3.3^{*}(2.2-5.0)$ & & $4.7 *(3.1-7.3)$ & \\
\hline 5 & $3.6 *(2.4-5.3)$ & & $2.8^{*}(1.7-4.6)$ & & $3.2^{*}(2.3-4.6)$ & & $4.3^{*}(2.0-9.5)$ & & $3.7 *(2.1-6.4)$ & \\
\hline $6+$ & $3.0 *(1.1-7.9)$ & & & & & & & & & \\
\hline \multicolumn{11}{|l|}{ II. Number of paternal } \\
\hline 1 & $1.6 *(1.5-1.7)$ & & $1.5^{*}(1.4-1.7)$ & & $1.6 *(1.5-1.7)$ & & $1.8^{*}(1.6-2.0)$ & & $1.8^{*}(1.5-2.0)$ & \\
\hline 2 & $2.0 *(1.8-2.3)$ & & $1.7 *(1.4-2.0)$ & & $2.0 *(1.7-2.4)$ & & $2.1 *(1.8-2.6)$ & & $2.5^{*}(1.9-3.3)$ & \\
\hline 3 & $2.2^{\star}(1.7-2.7)$ & & $2.1 *(1.6-2.8)$ & & $2.2^{*}(1.7-2.8)$ & & $1.9 *(1.2-3.0)$ & & $2.7 *(2.0-3.6)$ & \\
\hline 4 & $2.8^{*}(2.0-3.8)$ & & $2.4^{*}(1.7-3.3)$ & & $2.6 *(1.9-3.6)$ & & $2.7^{*}(1.6-4.5)$ & & $2.8^{*}(2.0-4.0)$ & \\
\hline 5 & $1.9 *(1.1-3.4)$ & & & & $1.9 *(1.1-3.2)$ & & & & & \\
\hline $6+$ & $2.0 *(1.1-3.6)$ & & & & & & & & & \\
\hline Globald $^{d}$ & & $1417.7^{*}$ & & $922.1^{*}$ & & $1113.6^{*}$ & & $508.7^{*}$ & & $685.1^{*}$ \\
\hline $\begin{array}{l}\text { a. Assessed in the Part II sa } \\
\text { b. For } \chi^{2} \text { d.f. }=2 \text {. } \\
\text { c. For number of parental d } \\
\text { represents } 5 \text { or more mater } \\
\text { d. For } \chi^{2} \text { d.f. }=12 \text {. Global ch } \\
\text { *Significant th the } 0.05 \text { level }\end{array}$ & $\begin{array}{l}\text { ample. Models inclu } \\
\text { disorders, the last o } \\
\text { rnal disorders. } \\
\text { ni-squared test for t } \\
\text { el, two-sided test. }\end{array}$ & $\begin{array}{l}\text { ude dummy } \\
\text { dds ratio re } \\
\text { the joint ass }\end{array}$ & $\begin{array}{l}\text { variables for numb } \\
\text { presents the odds } \\
\text { ociations of numbe }\end{array}$ & $\begin{array}{l}\text { er of paren } \\
\text { of the num } \\
\text { of parent }\end{array}$ & $\begin{array}{l}\text { mental disorders a } \\
\text { er or more. For ex } \\
\text { lisorders with each }\end{array}$ & $\begin{array}{l}\text { and control } \\
\text { ample, for } r \\
\text { of the offs }\end{array}$ & $\begin{array}{l}\text { or country, person } \\
\text { lood disorders, the } \\
\text { ring outcome diso }\end{array}$ & $\begin{array}{l}\text { jear, age } \\
\text { last odds } \\
\text { der classe }\end{array}$ & $\begin{array}{l}\text { id gender. } \\
\text { tio for maternal }\end{array}$ & rders \\
\hline
\end{tabular}

parent disorders predicting offspring disorders decrease as the number of comorbid parent disorders increases.

Disaggregation of this model shows that the same basic pattern of associations exists in predicting all four classes of offspring disorders. Every type of parent disorder is associated with elevated odds of offspring mood disorders; all types other than suicide death with offspring anxiety and behaviour disorders; and all types other than suicide attempt and suicide death with offspring substance disorders. Significant sub-additive interactions among parent disorders occur for both maternal and paternal disorders in predicting all classes of offspring disorder, with the exception of maternal disorders predicting offspring substance disorders. Patterns of within-class and between-class coefficients associated with types of parent disorders are similar to those in the additive model.

\section{Population-level associations of parent disorders with offspring disorders}

The PARPs based on the most complex multivariate model show that parent disorders explain, in a predictive sense, $12.4 \%$ of all offspring disorders $(9.8 \%$ of offspring mood disorders, $13.0 \%$ of anxiety disorders, $11.4 \%$ of substance disorders and $17.3 \%$ of behaviour disorders) (Table 5). Parent panic disorder has the largest disorder-specific PARP (5.5\% for all disorders, and 4.5$7.2 \%$ for disorder classes), whereas parent suicide attempt and death have the lowest PARPs. Disaggregation of results by income level of country (high, upper-middle and low/lower-middle) reveals remarkable consistency across country groups (Table 6). The highest PARP in all country groups is associated with parent disorders predicting offspring behaviour disorders. Parent panic disorder has the largest disorder-specific PARP in all country groups (5.2-6.1\% of all disorders) and parent suicide attempt and death have the lowest (0.1-1.4\% of all disorders). The PARPs are relatively comparable in high- and upper-middle-income countries and smaller in low/lower-middle-income countries ( $80 \%$ of comparisons). The PARP of all parent disorders predicting all offspring disorder is $13.6 \%$ in high-income, $13.6 \%$ in upper-middle-income and $8.7 \%$ in low/lower-middle-income countries.

\section{Discussion}

\section{Main findings}

This study provides novel information about the relationship between parent psychopathology and offspring mental disorders using data from a coordinated set of surveys conducted in 22 countries around the world. Study results indicated that each parent disorder examined, with the exception of suicide, was associated with increased risk for every class of offspring mental disorder. This pattern was evident even after controlling for the presence of comorbid parent disorders as well as for number of parent disorders. Although we found within-class associations involving pure parent disorders generally to be higher than across-class associations, this pattern was weak. We also found consistent evidence of sub-additive interactions, which means that the joint odds ratios of multiple parent disorders with offspring disorders are for the most part significantly less than the product of the odds ratios associated with the component pure disorders. At a population-level, parent disorders were associated with a meaningful (7.1-19.9\% across country and outcome disorder groups), although not overwhelming, proportion of all offspring disorders. To our knowledge, we provided the first estimates of the population-level influence of parent psychopathology on offspring disorders.

\section{Strengths and limitations}

The cross-national population-based nature of our data is unique and consequently may have produced results that are more generalisable than those reported from smaller and more selected samples. Nonetheless, these findings should be interpreted in light of study limitations. Most notably, parent disorders were assessed via informant reports made by their grown children. Although 
Table 4 Multivariate associations of types and number of parent psychopathology and mental disorders ${ }^{a}$

\begin{tabular}{|c|c|c|c|c|c|c|c|c|c|c|}
\hline \multirow[b]{3}{*}{ Parent disorder } & \multicolumn{10}{|c|}{ Offspring disorder } \\
\hline & \multicolumn{2}{|c|}{ Any disorder } & \multicolumn{2}{|c|}{ Mood disorder } & \multicolumn{2}{|c|}{ Anxiety disorder } & \multicolumn{2}{|c|}{ Substance disorder } & \multicolumn{2}{|c|}{ Behaviour disorder } \\
\hline & OR $(95 \% \mathrm{Cl})$ & $\chi^{2}$ & OR $(95 \% \mathrm{Cl})$ & $\chi^{2}$ & OR $(95 \% \mathrm{Cl})$ & $\chi^{2}$ & OR $(95 \% \mathrm{Cl})$ & $\chi^{2}$ & OR $(95 \% \mathrm{Cl})$ & $\chi^{2}$ \\
\hline \multicolumn{11}{|l|}{ I. Parent disorder } \\
\hline A. Depression ${ }^{\text {b }}$ & & $82.9 *$ & & $53.9 *$ & & $91.0 *$ & & $8.8^{*}$ & & $22.7^{\star}$ \\
\hline Exactly 1 parent & $1.8^{*}(1.6-2.1)$ & & $1.8^{*}(1.5-2.1)$ & & $1.9 *(1.7-2.3)$ & & $1.5^{*}(1.1-2.0)$ & & $1.8^{*}(1.4-2.3)$ & \\
\hline Both parents & $2.6^{*}(1.9-3.7)$ & & $2.6 *(1.8-3.9)$ & & $3.0 *(2.1-4.4)$ & & $1.1(0.5-2.8)$ & & $2.1^{\star}(1.2-3.6)$ & \\
\hline B. $G A D^{b}$ & & $123.7^{*}$ & & $85.4^{*}$ & & $146.4^{*}$ & & $11.6^{*}$ & & $38.5^{\star}$ \\
\hline Exactly 1 parent & $2.1^{*}(1.8-2.3)$ & & $2.0 *(1.7-2.3)$ & & $2.3^{*}(2.0-2.6)$ & & $1.5^{*}(1.2-1.9)$ & & $2.1 *(1.6-2.7)$ & \\
\hline Both parents & $3.0 *(2.1-4.3)$ & & $2.8^{*}(1.9-4.0)$ & & $3.4 *(2.3-5.0)$ & & $2.5^{*}(1.2-4.9)$ & & $3.1 *(1.9-5.1)$ & \\
\hline C. Panic disorder ${ }^{\text {b }}$ & & $362.4^{*}$ & & $217.6^{*}$ & & $366.3^{*}$ & & $71.5^{\star}$ & & $98.2^{*}$ \\
\hline Exactly 1 parent & $2.0 *(1.9-2.2)$ & & $2.0 *(1.8-2.2)$ & & $2.2^{*}(2.0-2.4)$ & & $1.8 *(1.6-2.1)$ & & $2.0 *(1.8-2.4)$ & \\
\hline Both parents & $3.0 *(2.5-3.6)$ & & $2.4^{*}(1.9-3.1)$ & & $3.5^{*}(2.8-4.3)$ & & $2.7 *(1.8-3.8)$ & & $2.9 *(2.1-4.1)$ & \\
\hline D. Substance misuse ${ }^{c}$ & & $156.6^{*}$ & & $70.6^{*}$ & & $90.1^{*}$ & & $121.1^{*}$ & & $37.3^{\star}$ \\
\hline $\begin{array}{l}\text { Exactly } 1 \text { parent - } \\
\text { mother } \\
\text { Exactly } 1 \text { parent - }\end{array}$ & $1.9^{*}(1.5-2.4)$ & & $1.7 *(1.3-2.3)$ & & $1.7 *(1.4-2.2)$ & & $2.2^{*}(1.7-3.0)$ & & $2.0 *(1.3-2.9)$ & \\
\hline father & $1.5^{*}(1.4-1.7)$ & & $1.4^{*}(1.3-1.6)$ & & $1.4^{*}(1.3-1.6)$ & & $2.0 *(1.7-2.3)$ & & $1.6 *(1.3-2.0)$ & \\
\hline Both parents & $2.6^{*}(2.0-3.4)$ & & $2.0 *(1.4-2.8)$ & & $2.6 *(1.9-3.5)$ & & $3.6 *(2.5-5.3)$ & & $2.3^{*}(1.6-3.5)$ & \\
\hline \multicolumn{11}{|c|}{ E. Antisocial personality } \\
\hline Exactly 1 parent & $1.9 *(1.7-2.1)$ & & $1.6 *(1.4-1.9)$ & & $1.9 *(1.7-2.1)$ & & $1.8 *(1.5-2.1)$ & & $2.3^{*}(1.8-2.8)$ & \\
\hline Both parents & $2.6^{*}(1.7-3.9)$ & & $1.8 *(1.0-3.2)$ & & $2.8 *(1.7-4.5)$ & & $2.5^{*}(1.3-4.6)$ & & $2.9 *(1.8-4.8)$ & \\
\hline F. Suicide attempt ${ }^{b}$ & & $32.6^{*}$ & & $23.9 *$ & & $24.2^{*}$ & & 5.7 & & $7.6^{*}$ \\
\hline Exactly 1 parent & $1.4^{*}(1.2-1.5)$ & & $1.4 *(1.2-1.6)$ & & $1.4^{*}(1.2-1.6)$ & & $1.2(1.0-1.5)$ & & $1.4^{*}(1.1-1.7)$ & \\
\hline Both parents & $1.5(0.9-2.8)$ & & $1.9(1.0-3.8)$ & & $1.9(0.9-3.8)$ & & $0.5(0.2-1.2)$ & & $1.8(0.8-4.0)$ & \\
\hline \multicolumn{11}{|l|}{ G. Suicide (death from } \\
\hline${\text { suicide })^{d}}^{d}$ & & $6.8^{*}$ & & $6.1^{*}$ & & 2.7 & & 2.9 & & 0.1 \\
\hline Any & $1.5^{\star}(1.1-2.1)$ & & $1.5^{*}(1.1-2.2)$ & & $1.4(0.9-2.1)$ & & $1.8(0.9-3.4)$ & & $1.1(0.4-3.3)$ & \\
\hline \multicolumn{11}{|l|}{ H. Global } \\
\hline $\begin{array}{l}\text { Global }^{e} \\
\text { Global for difference }\end{array}$ & & $670.0^{*}$ & & $419.8^{*}$ & & $553.7^{*}$ & & $227.2^{*}$ & & $201.8^{*}$ \\
\hline among types ${ }^{f}$ & & $64.2^{*}$ & & $51.8^{*}$ & & $81.4^{*}$ & & $47.4^{*}$ & & $28.6^{*}$ \\
\hline $\begin{array}{l}\text { II. Number of parent } \\
\text { disorders } \\
\text { A. Number of maternal } \\
\text { disorders }\end{array}$ & & $74.1^{*}$ & & $45.9^{*}$ & & $84.0^{*}$ & & 6.7 & & $19.4^{*}$ \\
\hline 2 & $0.6^{*}(0.5-0.8)$ & & $0.7 *(0.6-0.9)$ & & $0.6^{*}(0.5-0.7)$ & & $0.8(0.6-1.1)$ & & $0.7 *(0.6-1.0)$ & \\
\hline 3 & $0.5^{\star}(0.4-0.6)$ & & $0.5^{\star}(0.4-0.7)$ & & $0.4^{*}(0.3-0.6)$ & & $0.6 *(0.4-1.0)$ & & $0.6 *(0.4-1.0)$ & \\
\hline 4 & $0.3^{*}(0.2-0.4)$ & & $0.3^{*}(0.2-0.4)$ & & $0.2 *(0.1-0.3)$ & & $0.5(0.3-1.0)$ & & $0.4 *(0.2-0.9)$ & \\
\hline 5 & $0.2^{*}(0.1-0.3)$ & & $0.2 *(0.1-0.4)$ & & $0.1 *(0.1-0.2)$ & & $0.4^{*}(0.1-1.0)$ & & $0.2 *(0.1-0.4)$ & \\
\hline $6+$ & $0.1 *(0.0-0.3)^{*}$ & & & & & & & & & \\
\hline \multicolumn{11}{|c|}{ B. Number of paternal } \\
\hline 2 & $0.7 *(0.6-0.8)$ & & $0.7 *(0.6-0.9)$ & & $0.7 *(0.6-0.9)$ & & $0.8 *(0.6-1.0)$ & & $0.8(0.6-1.1)$ & \\
\hline 3 & $0.4^{*}(0.3-0.6)$ & & $0.5^{*}(0.4-0.7)$ & & $0.4^{*}(0.3-0.6)$ & & $0.4 *(0.3-0.8)$ & & $0.5^{*}(0.3-0.8)$ & \\
\hline 4 & $0.4^{\star}(0.2-0.6)$ & & $0.3^{*}(0.2-0.5)$ & & $0.3^{*}(0.2-0.5)$ & & $0.5(0.2-1.0)$ & & $0.3^{*}(0.1-0.6)$ & \\
\hline 5 & $0.2^{*}(0.1-0.3)$ & & & & $0.1 *(0.1-0.2)$ & & & & & \\
\hline $6+$ & $0.1^{*}(0.1-0.2)$ & & & & & & & & & \\
\hline \multicolumn{11}{|c|}{ C. Global test for number ${ }^{\text {h }}$} \\
\hline Global & & $103.9^{*}$ & & $62.3^{\star}$ & & $105.4^{*}$ & & 12.9 & & $23.7^{*}$ \\
\hline \multicolumn{11}{|c|}{$\begin{array}{l}\text { GAD, generalised anxiety disorder. } \\
\text { a. Assessed in the Part II sample. Models include dummy variables for both type and number of parent mental disorders and control for country, person-year, age and gender. } \\
\text { b. For } \chi^{2} \text { d.f. }=2 \text {. } \\
\text { d. Parent death from suicide is a time-varying predictor; all other parent disorders are not time-varying. For } \chi^{2} \text { d.f. }=1 . \\
\text { e. For } \chi^{2} \text { d.f. }=14 \text {. Global chi-squared test for the joint associations of all parent disorder types with each of the offspring outcome disorder classes. } \\
\text { f. For } \chi^{2} \text { d.f. }=12 \text {. Global chi-squared test to determine whether the odds ratios are the same for all parent disorder types. } \\
\text { g. For number of parental disorders, the last odds ratio represents the odds of the number or more. For example, for mood disorders, the last odds ratio for maternal disorders } \\
\text { represents five or more maternal disorders. No variable for exactly one parent disorder in included in the model, as this value is redundant with the information on types of disorders } \\
\text { For } \chi^{2} \text { d.f. }=5 . \\
\text { h. For } \chi^{2} \text { d.f. }=10 . \\
\text { *Significant at the } 0.05 \text { level, two-sided test. }\end{array}$} \\
\hline
\end{tabular}

known to provide useful information about the presence of mental disorders in relatives, ${ }^{30,31}$ this method of collecting information is susceptible to recall error and bias, ${ }^{34}$ with respondents who have a psychiatric disorder more likely than those without to report psychopathology in their family members. ${ }^{29,35}$ Because previous research suggests that respondents with a mental disorder are more likely than unaffected siblings to report that same disorder in a parent, ${ }^{29}$ any such bias would have inflated within-class associations in the current study. However, our results indicate less familial aggregation of specific disorder classes than prior studies. ${ }^{13}$

Second, the survey only assessed parent disorders present during the respondent's childhood. This likely resulted in underreporting of parent disorders, given that respondents may not have had a full appreciation of parental symptoms. If respondents consequently reported only the most severe parent disorders, this may have inflated estimates of parent-offspring disorder 
Table 5 Population attributable risk proportions (PARP) of parent psychopathology predicting lifetime mental disorders in the total sample ${ }^{a}$

\begin{tabular}{|lccccc|}
\hline All countries & Any disorder & Mood disorder & Anxiety disorder & Substance disorder & Behaviour disorder \\
\hline Parent depression & 2.63 & 2.22 & 3.10 & 1.42 & 3.83 \\
\hline Parent generalised anxiety disorder & 3.36 & 2.85 & 4.02 & 1.77 & 4.95 \\
\hline Parent panic disorder & 5.46 & 4.48 & 6.18 & 4.37 & 7.23 \\
\hline Parent substance misuse & 3.16 & 1.96 & 2.59 & 5.02 & 4.97 \\
\hline Parent antisocial personality disorder & 2.19 & 1.20 & 2.08 & 2.29 & 4.52 \\
\hline Parent suicide attempt & 0.98 & 0.85 & 1.00 & 0.46 & 1.45 \\
\hline Parent death by suicide & 0.07 & 0.09 & 0.04 & 112 & 0.02 \\
\hline All parent disorders & 12.37 & 9.81 & 13.00 & 11.41 & 17.28 \\
$\begin{array}{l}\text { a. The model presented in Table 4 was used to estimate the PARP. Each row displays the proportion of disorder onsets in the population that are attributable to each parental disorder. } \\
\text { The final row of the table shows the proportion of disorder onsets in the population that are attributable to all parental disorders jointly. }\end{array}$ \\
\hline
\end{tabular}

Table 6 Population attributable risk proportions (PARP) of parent psychopathology predicting lifetime mental disorders disaggregated by country income group ${ }^{a}$

\begin{tabular}{|c|c|c|c|c|c|}
\hline Country & Any disorder & Mood disorder & Anxiety disorder & Substance disorder & Behaviour disorder \\
\hline \multicolumn{6}{|l|}{ I. High income } \\
\hline Parent depression & 2.45 & 2.06 & 2.73 & 1.22 & 3.15 \\
\hline Parent generalised anxiety disorder & 4.17 & 3.45 & 4.81 & 2.18 & 6.13 \\
\hline Parent panic disorder & 5.22 & 3.73 & 5.83 & 4.72 & 6.13 \\
\hline Parent substance misuse & 4.25 & 2.78 & 3.72 & 6.24 & 5.67 \\
\hline Parent antisocial personality disorder & 2.84 & 1.49 & 2.63 & 2.63 & 5.96 \\
\hline Parent suicide attempt & 1.44 & 1.17 & 1.42 & 0.54 & 2.24 \\
\hline Parent death by suicide & 0.08 & 0.11 & 0.04 & 0.20 & -0.13 \\
\hline All parent disorders & 13.64 & 10.23 & 13.97 & 12.82 & 18.47 \\
\hline \multicolumn{6}{|l|}{ II. Upper-middle income } \\
\hline Parent depression & 2.80 & 2.15 & 3.46 & 0.92 & 4.49 \\
\hline Parent generalised anxiety disorder & 4.26 & 3.70 & 4.73 & 1.94 & 5.51 \\
\hline Parent panic disorder & 6.14 & 4.86 & 6.74 & 4.59 & 9.90 \\
\hline Parent substance misuse & 2.82 & 1.59 & 1.64 & 5.09 & 6.17 \\
\hline Parent antisocial personality disorder & 2.00 & 1.33 & 1.64 & 2.41 & 3.26 \\
\hline Parent suicide attempt & 0.87 & 0.86 & 1.14 & -0.38 & 0.78 \\
\hline Parent death by suicide & 0.07 & 0.21 & 0.07 & -0.03 & -0.07 \\
\hline All parent disorders & 13.63 & 10.98 & 13.70 & 11.71 & 19.89 \\
\hline \multicolumn{6}{|l|}{ III. Low/lower-middle income } \\
\hline Parent depression & 2.23 & 2.08 & 2.89 & 0.83 & 3.04 \\
\hline Parent generalised anxiety disorder & 0.96 & 1.11 & 1.21 & 0.01 & 0.78 \\
\hline Parent panic disorder & 5.69 & 5.71 & 6.45 & 3.71 & 7.20 \\
\hline Parent substance misuse & 1.25 & 0.78 & 0.83 & 2.43 & 2.08 \\
\hline Parent antisocial personality disorder & 0.97 & 0.38 & 1.08 & 1.28 & 1.54 \\
\hline Parent suicide attempt & 0.13 & 0.30 & -0.04 & 0.29 & -0.20 \\
\hline Parent death by suicide & 0.09 & 0.00 & 0.06 & 0.12 & 0.30 \\
\hline All parent disorders & 8.70 & 8.12 & 9.48 & 7.08 & 10.99 \\
\hline
\end{tabular}

associations. On the other hand, lack of information on parent disorders occurring later in the respondent's life likely produced conservative estimates of the associations between parent and offspring disorders.

Third, the WMH Surveys do not have a genetically informative design, making it impossible to estimate the heritability of specific disorders or determine the proportion of parent-offspring disorder associations that were due to genetic $v$. environmental factors.

Fourth, we focused only on a small number of common parent disorders rather than on more severe but uncommon disorders (such as psychotic disorders). Because familial transmission is likely to be most evident for severe disorders, ${ }^{14}$ inclusion of less severe parent disorders would have attenuated associations with offspring disorders. Finally, although PARP is a joint function of the prevalence of parent disorder and the strength of association with offspring disorders, we did not distinguish between these two factors in our comparisons across country groups. Examination of these joint effects at a disaggregated country level represents an important area for future research.

\section{Comparison with previous findings}

Within the context of these limitations, our results are similar to those of previous studies in documenting significant associations between parent and offspring disorders. Indeed, we found that virtually every type of parent mental disorder was associated with elevated odds of every class of offspring disorder. This was true even after accounting for type and number of comorbid parent disorders. Because the controls for number of disorders can be interpreted as pooled interactions, the net associations of individual parent disorders with offspring disorders (in the model that controls number of disorders) can be interpreted as the 
estimated associations of pure parent disorders (i.e. comparisons between parents who had a history of only that one disorder $v$. parents who had no disorders) with offspring disorders. This means that pure parent disorders have relatively pervasive associations with offspring disorders.

We found less familial aggregation of specific disorder classes than many prior studies, ${ }^{5,6,11}$ with little specificity in the associations of particular parent disorders with particular offspring disorders, other than a modest pattern of within-class associations being larger than across-class associations. This pattern is indirectly consistent with research suggesting that most genetic liability factors are associated with a propensity to experience internalising and externalising pathology rather than with elevated risk of specific disorders. ${ }^{9,12,36}$ Other data consistent with this general pattern has been reported, such as a finding that parent depression was associated with increased risk for a wide range of offspring disorders ${ }^{5}$ and that numerous parent disorders were associated with offspring social phobia. ${ }^{11}$ Although other studies found more specificity in the intergenerational transmission of particular disorders, including anxiety disorders, ${ }^{1,10}$ substance use disorders, ${ }^{6}$ behavioural disorders ${ }^{3}$ and major depression, ${ }^{5}$ the majority of these studies were based on relatively small samples and examined only a single or limited number of parent disorders. The few previous studies with sufficient sample sizes that included controls for comorbid disorders have typically found a more generalised pattern of intergenerational transmission of mental disorders similar to the pattern found here. ${ }^{2,12,36}$

This pattern raises important questions about why parent psychopathology is a relatively non-specific risk factor for offspring disorders. One possibility is that parents with mental disorders not only transmit genetic vulnerability to their offspring, but also are more likely than parents without psychopathology to engage in negative parenting behaviours that do not vary substantially by type of parent disorder. ${ }^{4,11,37}$ Consistent with this possibility, parent psychopathology has been associated in several studies with a wide range of maladaptive family-related adversities, such as maltreatment and family violence. ${ }^{16,17,38}$ These adversities, in turn, have been shown to be robust and relatively non-specific risk factors of adult psychiatric disorders. ${ }^{16,17}$

Our findings that the associations of maternal and paternal psychopathology with offspring disorders were relatively similar, that these associations did not vary by gender of offspring and that the odds of offspring disorder were consistently higher when both parents had a disorder rather than only one parent are all broadly consistent with previous research. ${ }^{5,39}$ Although parent-offspring associations within-disorder classes were found to be generally stronger than across-class associations, these patterns were weak and had some exceptions, such as parent generalised anxiety disorder and panic disorder predicting offspring mood disorders more strongly than parent depression. Most of these deviations are consistent with evidence from behaviour genetics research that genetic liability factors broadly predispose individuals to develop internalising pathology ${ }^{9}$ and that similar genetic factors underlie generalised anxiety disorder and depression ${ }^{8}$ as well as generalised anxiety disorder and panic disorder. ${ }^{7}$ We also found that parent depression and generalised anxiety disorder were associated with offspring behaviour disorders as strongly as parent antisocial personality disorder. This pattern is similar to the previous finding of a high degree of familial co-aggregation between depressive and behavioural disorders. ${ }^{40}$

The pervasive pattern of sub-additive interactions among comorbid parent disorders in predicting offspring disorders reported here represents a unique contribution of this study. This pattern mirrors associations observed among a wide range of childhood adversities in predicting subsequent first onset of mental disorders ${ }^{16,17}$ as well as associations among temporally primary disorders in predicting the subsequent first onset of other secondary disorders. ${ }^{15}$ It is important to recognise that these negative interactions do not mean that additional parent disorders are associated with decreased risk of offspring disorders, but that increases in risk occur at a decreasing rate. This can be seen most clearly in Table 3, where we find that the odds ratios associated with high parent comorbidity are elevated but not dramatically higher than the odds ratios associated with lower numbers of parent disorders. We observed these sub-additive interactions for all disorder classes in offspring, other than for the association of maternal disorders with offspring substance disorders.

\section{Implications}

Our findings suggest that future behaviour genetics studies should both assess comorbid parent disorders and utilise appropriate statistical models to account for the non-additive associations of comorbid parent disorders with offspring disorders. To the extent that the sub-additive interactions reflect causal effects of parent disorders, this pattern implies that intervening to treat any single parent disorder in the presence of comorbidity would likely have little effect on offspring disorder, as odds of offspring disorder are not markedly lower in the presence of a small compared with a large number of parent disorders. Effective interventions to prevent offspring disorders would consequently require intervening so as to protect the child from the full range of parent disorders. Given that parent disorders are robust predictors of offspring disorders across all the disorder classes and country groups considered here, it is important to recognise the potential public health importance of such interventions not only to improve the functioning of mentally ill parents but also to reduce the intergenerational transmission of mental disorders.

Katie A. McLaughlin, PhD, Division of General Pediatrics, Children's Hospital Boston and Harvard Medical School, Boston, Massachusetts, USA; Anne M. Gadermann PhD, Irving Hwang, MA, Nancy A. Sampson, BA, Department of Health Care Policy, Harvard Medical School, Boston, Massachusetts, USA; Ali Al-Hamzawi, MBChB, MD, FICMS, Al-Qadisia University College of Medicine, Diwania Governorate, Iraq; Laura Helena Andrade, MD, PhD, Section of Psychiatric Epidemiology - LIM 23 , Institute of Psychiatry, University of São Paulo Medical School, São Paulo, Brazil; Institute of Psychiatry, University of Säo Paulo Medical School, São Paulo, Brazil,
Matthias C. Angermeyer, MD, Center for Public Mental Health, Gösing am Wagram, Austria; Corina Benjet, PhD, Division of Epidemiologic and Psychosocial Research, National Institute of Psychiatry Ramón de la Fuente, Mexico City, Mexico; Evelyn J. Bromet, PhD, Department of Psychiatry, State University of New York at Stony Brook, Stony Brook, New York; Ronny Bruffaerts, PhD, Universitair Psychiatrisch Centrum Katholieke Universiteit Leuven (UPC-KUL), Leuven, Belgium; José Miguel Caldas-deAlmeida, MD, PhD, Chronic Diseases Research Center (CEDOC) and Department of Almeida, MD, PhD, Chronic Diseases Research Center (CEDOC) and Department of
Mental Health, Faculdade de Ciências Médicas, Universidade Nova de Lisboa, Lisbon, Portugal; Giovanni de Girolamo, MD, IRCCS Centro San Giovanni di Dio

Fatebenefratelli Brescia, Italy; Ron de Graaf, PhD, MSc, Netherlands Institute of Mental Health and Addiction, Utrecht, The Netherlands; Silvia Florescu, MD, PhD, National School of Public Health Management and Professional Development,

Bucharest, Romania; Oye Gureje, MD, PhD, FRCPsych, University College Hospital,

Ibadan, Nigeria; Josep Maria Haro, MD, MPH, PhD, Parc Sanitari Sant Joan de Déu, CIBERSAM, Universitat de Barcelona, Sant Boi de Llobregat, Barcelona, Spain; Hristo Ruskov Hinkov, MD, National Center for Public Health Protection, Sofia, Bulgaria; Itsuko Horiguchi, DDS, PhD, Department of Public Health, Juntendo University Graduate School of Medicine, Tokyo, Japan; Chiyi Hu, MD, PhD, Shenzhen Institute of Mental Health \& Shenzhen Kangning Hospital, Shenzhen, People's Republic of China; Aimee Nasser Karam, PhD, Department of Psychiatry and Clinical Psychology, Saint George Hospital University Medical Center, Balamand University Medical School and the Institute for Development, Research, Advocacy and Applied Care (IDRAAC), Beirut, Lebanon; Viviane Kovess-Masfety, MD, PhD, EA 4069 Université Paris Descartes \& EHESP School for Public Health Department of Epidemiology, Paris, France; Sing Lee, MB, BS, FRCPsych, The Chinese University of Hong Kong, Hong Kong, People's Republic of China; Samuel D. Murphy, BSC, MSc, PhD, School of Psychology, University of Ulster, Londonderry, Northern Ireland; $\mathbf{S}$. Haque Nizamie, PhD, Central Institute of Psychiatry, Ranchi, Jharkhand, India; José Posada-Villa, MD, Instituto Colombiano del Sistema Nervioso, Bogota DC, Colombia; David R. Williams, MPH, Colombiano del Sistema Nervioso, Bogota DC, Colombia; David R. Williams, MPH,
PhD, Department of Society, Human Development and Health, Harvard School of Public Health, Boston, Massachusetts, USA; Ronald C. Kessler, PhD, Department of Health Care Policy, Harvard Medical School, Boston, Massachusetts, USA

Correspondence: Katie A. McLaughlin, Division of General Pediatrics, Children's Hospital Boston, Harvard Medical School, 300 Longwood Ave, Boston, MA 02115, USA. Email: Katie.McLaughlin@childrens.harvard.edu

First received 12 Aug 2011, final revision 16 Nov 2011, accepted 19 Dec 2011 


\section{Funding}

The World Health Organization (WHO) World Mental Health (WMH) Survey Initiative was supported by the United States National Institute of Mental Health (R01MH070884, R01MH093612), NIMH - Mental Health Burden Study: Contract number HHSN271200700030C the John D. and Catherine T. MacArthur Foundation, the Pfizer Foundation, the US Public Health Service (R13-MH066849, R01-MH069864 and R01 DA016558), the Fogarty International Center (FIRCA R03-TW006481), the Pan American Health Organization (PAHO), the Eli Lilly \& Company Foundation, Ortho-McNeil Pharmaceutical, GlaxoSmithKline, Bristol-Myers Squibb and Shire. Each WMH country obtained funding for its own survey. The São Paulo Megacity Mental Health Survey is supported by the State of São Paulo Research Foundation (FAPESP) Thematic Project Grant 03/00204-3. The Bulgarian Epidemiological Study of common mental disorders EPIBUL is supported by the Ministry of Health and the National Center for Public Health Protection. The Chinese World Mental Health Survey Initiative is supported by the Pfizer Foundation. The Shenzhen Mental Health Survey is supported by the Shenzhen Bureau of Health and the Shenzhen Bureau of Science, Technology, and Information. The Colombian National Study of Mental Health (NSMH) is supported by the Ministry of Social Protection. The ESEMeD project is funded by the European Commission (Contracts QLG5-1999-01042; SANCO 2004123), the Piedmont Region (Italy), Fondo de Investigación Sanitaria, Instituto de Salud Carlos III, Spain (FIS 00/ 0028), Ministerio de Ciencia y Tecnología, Spain (SAF 2000-158-CE), Departament de Salut, Generalitat de Catalunya, Spain, Instituto de Salud Carlos III (CIBER CB06/02/0046, RETICS RD06/0011 REM-TAP) and other local agencies and by an unrestricted educational grant from GlaxoSmithKline. The Epidemiological Study on Mental Disorders in India was funded jointly by Government of India and WHO. Implementation of the Iraq Mental Health Surve (IMHS) and data entry were carried out by the staff of the Iraqi MOH and MOP with direc support from the Iraqi IMHS team with funding from both the Japanese and European Funds through United Nations Development Group Iraq Trust Fund (UNDG ITF). The World Mental Health Japan (WMHI) Survey is supported by the Grant for Research on Psychiatric and Neurological Diseases and Mental Health (H13-SHOGAI-023, H14-TOKUBETSU-026, H16KOKORO-013) from the Japan Ministry of Health, Labour and Welfare. The Lebanese National Mental Health Survey (LEBANON) is supported by the Lebanese Ministry of Public Health, the WHO (Lebanon), National Institute of Health/Fogarty International Center (R03 TW006481-01), anonymous private donations to IDRAAC, Lebanon, and unrestricted grants from Janssen Cilag, Eli Lilly, GlaxoSmithKline, AstraZeneca, Hikma Pharm and Novartis. The Mexican National Comorbidity Survey (MNCS) is supported by The National Institute of Psychiatry Ramon de la Fuente (INPRFMDIES 4280) and by the National Council on Science and Technology (CONACYT-G30544-H), with supplemental support from PAHO. The Nigerian Survey of Mental Health and Wellbeing (NSMHW) is supported by the WHO (Geneva), the WHO (Nigeria) and the Federal Ministry of Health, Abuja, Nigeria. The Northern Ireland Study of Mental Health was funded by the Health \& Social Care Research \& Development Division of the Public Health Agency. The Portuguese Mental Health Study was carried out by the Department of Mental Health, Faculty of Medical Sciences, NOVA University of Lisbon, with collaboration of the Portuguese Catholic University, and was funded by champalimaud Foundation, Gulbenkian Foundation, Foundation for science and Champalimaud Foundation, Gulbenkian Foundation, Foundation for Science and
Technology (FCT) and Ministry of Health. The Romania WMH study projects 'Policies in Mental Health Area' and 'National Study regarding Mental Health and Services Use' were carried out by National School of Public Health \& Health Services Management (forme National Institute for Research \& Development in Health, present National School of Public Health Management \& Professional Development, Bucharest), with technical support of Metro Media Transilvania the National Institute of Statistics - National Centre for Training in Statistics, SC. Cheyenne Services SRL, Statistics Netherlands and were funded by in Statistics, SC. Cheyenne Services SRL, Statistics Netherlands and were funded by Romania SRL. The South Africa Stress and Health Study (SASH) is supported by the US National Institute of Mental Health (R01-MH059575) and National Institute of Drug Abuse with supplemental funding from the South African Department of Health and the University of Michigan. The Ukraine Comorbid Mental Disorders during Periods of Social Disruption (CMDPSD) study was funded by the US National Institute of Mental Health (RO1 MH61905). The US National Comorbidity Survey Replication (NCS-R) is supported by the National Institute of Mental Health (U01-MH60220) with supplemental support from the National Institute of Drug Abuse, the Substance Abuse and Mental Health Services Administration, the Robert Wood Johnson Foundation (grant 044708) and the John W. Alden Trust.

\section{Acknowledgements}

We thank the WHO WMH staff for assistance with instrumentation, fieldwork and data analysis. A complete list of all within-country and cross-national WMH publications can be found at www.hcp.med.harvard.edu/wmh/.

\section{References}

1 Beidel DC, Turner SM. At risk for anxiety: I. Psychopathology in the offspring of anxious parents. J Am Acad Child Adolesc Psychiatry 1997; 36: 918-24.

2 Bornovalova MA, Hicks BM, Iacono WG, McGue M. Familial transmission and heritability of childhood disruptive disorders. Am J Psychiatry 2010; 167: $1066-74$.

3 Clark DB, Cornelius J, Wood DS, Vanyukov M. Psychopathology risk transmission in children of parents with substance use disorders. Am J Psychiatry 2004; 161: 685-91.

4 Downey G, Coyne JC. Children of depressed parents: an integrative review. Psychol Bull 1990; 108: 50-76.

5 Lieb R, Isensee B, Hofler M, Pfister $\mathrm{H}$, Wittchen HU. Parental majo depression and the risk of depression and other mental disorders in offspring: a prospective-longitudinal community study. Arch Gen Psychiatry 2002; 59: 365-74.

6 Merikangas KR, Stolar M, Stevens DE, Goulet J, Preisig MA, Fenton B, et al. Familial transmission of substance use disorders. Arch Gen Psychiatry 1998; 55: 973-9.

7 Hettema JM, Prescott CA, Myers JM, Neale MC, Kendler KS. The structure of genetic and environmental risk factors for anxiety disorders in men and women. Arch Gen Psychiatry 2005; 62: 182-9.

8 Kendler KS, Neale MC, Kessler RC, Heath AC, Eaves L. Major depression and generalized anxiety disorder. Same genes, (partly) different environments? Arch Gen Psychiatry 1992; 49: 716-22.

9 Kendler KS, Prescott CA, Myers J, Neale MC. The structure of genetic and environmental risk factors for common psychiatric and substance use disorders in men and women. Arch Gen Psychiatry 2003; 60: 929-37.

10 Biederman J, Petty C, Faraone SV, Henin A, Hirshfeld-Becker D, Pollack MH, et al. Effects of parental anxiety disorders in children at high risk for panic disorder: a controlled study. J Affect Disord 2006; 94: 191-7.

11 Lieb R, Wittchen HU, Hofler M, Fuetsch M, Stein MB, Merikangas KR. Parental psychopathology, parenting styles, and the risk of social phobia in offspring: a prospective-longitudinal community study. Arch Gen Psychiatry 2000; 57: 859-66

12 Kendler KS, Davis CG, Kessler RC. The familial aggregation of common psychiatric and substance use disorders in the National Comorbidity Survey: a family history study. Br J Psychiatry 1997; 170: 541-8.

13 Low NC, Cui L, Merikangas KR. Specificity of familial transmission of anxiety and comorbid disorders. J Psychiatr Res 2008; 42: 596-604.

14 Merikangas KR, Stevens DE, Fenton B, Stolar M, O'Malley S, Woods SW, et al. Co-morbidity and familial aggregation of alcoholism and anxiety disorders. Psychol Med 1998; 28: 773-88.

15 Kessler RC, Ormel J, Petukhova M, McLaughlin KA, Green JG, Russo $\sqcup$, et al. Development of lifetime comorbidity in the World Health Organization world mental health surveys. Arch Gen Psychiatry 2011; 68: 90-100.

16 Green JG, McLaughlin KA, Berglund PA, Gruber MJ, Sampson NA, Zaslavsky $A M$, et al. Childhood adversities and adult psychiatric disorders in the national comorbidity survey replication I: associations with first onset of DSM-IV disorders. Arch Gen Psychiatry 2010; 67: 113-23.

17 Kessler RC, McLaughlin KA, Green JG, Gruber MJ, Sampson NA, Zaslavsky $\mathrm{AM}$, et al. Childhood adversities and adult psychopathology in the WHO World Mental Health Surveys. Br J Psychiatry 2010; 197: 378-85.

18 World Bank. Data \& Statistics, Country Groups by Income. World Bank, 2009 (http://go.worldbank.org/D7SNOB8YU0).

19 American Psychiatric Association. Diagnostic and Statistical Manual of Mental Disorders (4th edn) (DSM-IV). APA, 1994.

20 Harkness J, Pennell BE, Villar A, Gebler N, Aguilar-Gaxiola S, Bilgen I. Translation procedures and translation assessment in the World Mental Health Survey Initiative. In The WHO World Mental Health Surveys: Global Perspectives on the Epidemiology of Mental Disorders (eds RC Kessler, TB Üstün): 91-113. Cambridge University Press, 2008.

21 Heeringa SG, Wells EJ, Hubbard F, Mneimneh ZN, Chiu WT, Sampson NA, et al. Sample designs and sampling procedures. In The WHO World Mental Health Surveys: Global Perspectives on the Epidemiology of Mental Disorders (eds RC Kessler, TB Üstün): 14-32. Cambridge University Press, 2008.

22 Pennell B-E, Mneimneh Z, Bowers A, Chardoul S, Wells JE, Viana MC, et al. Implementation of the World Mental Health Surveys. In The WHO World Mental Health Surveys: Global Perspectives on the Epidemiology of Mental Disorders (eds RC Kessler, TB Üstün): 33-57. Cambridge University Press, 2008

23 Kessler RC, Üstün TB. The World Mental Health (WHM) Survey Initiative Version of the World Health Organization (WHO) Composite International Diagnostic Interview (CIDI). Int J Methods Psychiatr Res 2004; 13: 93-121.

24 Haro JM, Arbabzadeh-Bouchez S, Brugha TS, di Girolamo G, Guyer M, Jin R, et al. Concordance of the Composite International Diagnostic Interview Version 3.0 (CIDI 3.0) with standardized clinical assessments in the WHO World Metnal Health Surveys. Int J Methods Psychiatr Res 2006; 15: 167-80.

25 First M, Spitzer RL, Gibbon M, Williams JBW. Structured Clinical Interview for DSM-IV Axis I Disorders, Research Version, Non-patient Edition (SCID-I/NP). Biometrics Research, New York State Psychiatric Institute, 2002.

26 Knauper B, Cannell CF, Schwarz N, Bruce ML, Kessler RC. Improving the accuracy of major depression age of onset reports in the US National Comorbidity Survey. Int J Methods Psychiatr Res 1999; 8: 39-48.

27 Kessler RC, Angermeyer M, Anthony JC, de Graaf R, Demyttenaere K, Gasquet I, et al. Lifetime prevalence and age-of-onset distributions of mental disorders in the World Health Organization's World Mental Health Survey Initiative. World Psychiatry 2007; 6: 168-76. 
28 Endicott J, Andreasen N, Spitzer RL. Family History Research Diagnostic Criteria. Biometrics Research, New York State Psychiatric Institute, 1978.

29 Kendler KS, Silberg JL, Neale MC, Kessler RC, Heath AC, Eaves LJ. The family history method: whose psychiatric history is measured? Am J Psychiatry 1991; 148: 1501-4.

30 Kendler KS, Roy MA. Validity of a diagnosis of lifetime major depression obtained by personal interview versus family history. Am J Psychiatry 1995; 152: $1608-14$

31 Prescott CA, Sullivan PF, Myers JM, Patterson DG, Devitt M, Halberstadt L et al. The Irish Affected Sib Pair Study of Alcohol Dependence: study methodology and validation of diagnosis by interview and family history. Alcohol Clin Exp Res 2005; 29: 417-29.

32 Efron B. Logistic regression, survival analysis, and the Kaplan-Meier curve. J Am Stat Assoc 1988; 83: 414-25.

33 Wolter KM. Introduction to Variance Estimation. Springer-Verlag, 1985

34 Roy MA, Walsh D, Kendler KS. Accuracies and inaccuracies of the family history method: a multivariate approach. Acta Psychiatr Scand 1996; 93 224-34
35 Milne BJ, Caspi A, Crump R, Poulton R, Rutter M, Sears MR, et al. The validity of the family history screen for assessing family history of mental disorders. Am J Med Genet B Neuropsychiatr Genet 2009; 150B: 41-9.

36 Hicks BM, Krueger RF, Iacono WG, McGue M, Patrick CJ. Family transmission and heritability of externalizing disorders: a twin-family study. Arch Gen Psychiatry 2004; 61: 922-8.

37 Chen $\mathrm{M}$, Johnston $\mathrm{C}$. Maternal inattention and impulsivity and parenting behaviors. J Clin Child Adolesc Psychol 2007; 36: 455-68.

38 Conron KJ, Beardslee W, Koenen KC, Buka SL, Gortmaker SL. A longitudinal study of maternal depression and child maltreatment in a national sample of families investigated by child protective services. Arch Pediatr Adolesc Med 2009; 163: 922-30.

39 Dierker LC, Merikangas KR, Szatmari P. Influence of parental concordance for psychiatric disorders on psychopathology in offspring. J Am Acad Child Adolesc Psychiatry 1999; 38: 280-8.

40 Biederman J, Faraone SV, Hirshfeld-Becker DR, Friedman D, Robin JA, Rosenbaum JF. Patterns of psychopathology and dysfunction in high-risk children of parents with panic disorder and major depression. Am J Psychiatry 2001; 158: 49-57.

\section{poems by doctors}

\section{The Motorcyclist}

\section{Colin Begg}

At most deaths I have not noticed the faces preferring the distraction of tubes and signs and CPR, focusing on small detail

not the unclinical tableau of this man found stretched on his back over gravel and tarmac

near the high pass

on this bluest of leisure sundays

We cut off his leathers

the district nurse, the off-duty paramedic

the mountain rescuer and I

while a kayaker kept his neck in line

His stove chest was gasping

His carotid pulse a fading stammer - stop.

And we kept him going ten, fifteen rib-crunching minutes until an ambulance came with proper kit

and I could taste the tar of his last cigarette as I upped the technology, slipped a clearly futile tube in his trachea and we kept on, spurred by distant rotors and Helimed sets down in shallow bracken, how suddenly strange, my city colleagues are

Thirty-plus now and no pulse, the outcome set. congent, I look around -

and all our faces are that absent metaphor for how it feels to try and fail to save a life. sore-kneed, I look down -

and see on his, a day's stubble

and the keenest blue

around his fixed, dilated pupils

This poem is from The Hippocates Prize 2011, published by published by The Hippocrates Prize in association with Top Edge Press.

Chosen by Femi Oyebode.
The British Journal of Psychiatry (2012) 200, 299. doi: 10.1192/bjp.bp.111.103036 